\title{
Self-standing electrochemical double layer capacitors for operation in severe temperature conditions
}

\author{
C. Lecoeur $\cdot$ B. Daffos $\cdot$ R. Lin $\cdot$ L. Divay $\cdot$ \\ P. Le Barny $\cdot$ M. Pham Thi $\cdot$ P.-L. Taberna \\ P. Simon
}

Received: 24 January 2013/ Accepted: 25 March 2013/Published online: 26 April 2013

(C) The Author(s) 2013. This article is published with open access at Springerlink.com

\begin{abstract}
Safe and ecological electrochemical double layer capacitors (EDLCs) are nowadays needed as energy sources for wearable electronics working in hard temperature conditions. Here, we report a method based on the use of an organic solvent without any surfactant to synthesize a self-supported paper-like electrode composed solely by multiwall carbon nanotubes, named buckypapers. Using an eutectic mixture of ionic liquids (1:1 in molar ratio), $N$-methyl- $N$-propylpiperidinium bis(fluorosulfonyl)imide and $N$-butyl- $N$-methylpyrrolidinium bis(fluorosulfonyl) imide, as electrolyte, EDLCs based on buckypapers were assembled and tested up to $3 \mathrm{~V}$. Ionic liquids are well known as green solvents for the environment and are safe for humans in their use thanks to their low vapor pressure. In addition to these problems of security solved, this electrolyte allows working in a wide temperature range, i.e. from -50 to $+100{ }^{\circ} \mathrm{C}$, delivering capacitances similar to those obtained in usual organic solvents.
\end{abstract}

Keywords Energy storage - Electrochemical double layer capacitor · Buckypapers · Carbon nanotube - Ionic liquid

C. Lecoeur · B. Daffos · R. Lin · P.-L. Taberna $(\varangle) \cdot$ P. Simon Centre Interuniversitaire de Recherche et d'Ingénierie des Matériaux CIRIMAT, UMR CNRS 5085, Université Paul Sabatier, 118 route de Narbonne, 31062 Toulouse Cedex 09, France

e-mail: taberna@chimie.ups-tlse.fr

C. Lecoeur - B. Daffos · R. Lin · P.-L. Taberna - P. Simon Réseau sur le Stockage Electrochimique de l'Energie (RS2E), FR CNRS 3459, Toulouse, France

L. Divay · P. Le Barny · M. P. Thi

Thales Research and Technology, Campus Polytechnique, 1 avenue Augustin Fresnel, 91767 Palaiseau Cedex, France

\section{Introduction}

Electrochemical double layer capacitors (EDLCs) fill the gap between conventional capacitors and batteries. They show higher energy densities but lower power densities than capacitors, while exhibiting higher power densities but lower energy densities than batteries [1]. EDLCs are used in a wide range of applications, alone or in combination with batteries [2-5]. With the development of portable and wearable electronic devices, energy storage systems (ESS) like batteries and EDLCs must become smaller, lighter, thinner and indeed more flexible while maintaining the same level of performance. One of the limitation in the use of ESS like EDLCs lies in the operating temperature range that is today limited between -25 and $+70{ }^{\circ} \mathrm{C}$ for carbonate-based electrolytes and from -40 and $+70{ }^{\circ} \mathrm{C}$ for acetonitrile-based solutions [6, 7]. Widening this temperature range would open the use of EDLCs in power electronics in severe environments such as one can find in aeronautics, space, automotive or military applications for outdoor operations $[8,9]$.

Recently, we showed that thanks to the combination of exohedral carbons offering a fully accessible surface area with a low melting point ionic liquids (ILs) eutectic mixture, an operation temperature range between -50 and $+100{ }^{\circ} \mathrm{C}$ could be achieved [10]. However, the specific capacitance of the carbon nanotubes (CNTs) grown from an $\mathrm{Al}$ foil was low, at about $3 \mathrm{mF} \mathrm{cm}{ }^{-2}$ of electrode, mainly because of the small mass loading $\left(0.2 \mathrm{mg} \mathrm{cm}^{-2}\right)$.

The flexibility of CNTs buckypapers (BPs), widely studied at room temperature [11-14], confers an interesting feature for using these EDLCs in smart-textile applications $[15,16]$. In the present paper, we report results on the design of self-supported electrodes for small-size EDLCs for operation within a large temperature range, based on the use of buckypapers (BPs).

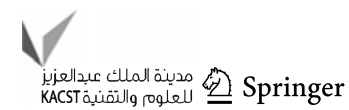




\section{Experimental}

Buckypaper synthesis

Nanotube networks also called buckypaper are generally obtained by special infiltration of aqueous nanotube suspension using a surfactant $[17,18]$. We have developed a method based on the use of an organic solvent without any surfactant. A mixture of $150 \mathrm{mg}$ of carbon nanotubes (MWCNT $>95 \%$, Aldrich) in $500 \mathrm{~mL}$ of $N$-methylpyrrolidine (NMP, $98 \%$, Alfa-Aesar) is sonicated for $3 \mathrm{~h}$. The obtained suspension is centrifuged at 3,000 rpm for $20 \mathrm{~min}$ so that the MWCNT bundles are discarded. The suspension is then filtered off under a pressure of 3.5 bars, through a $0.45 \mu \mathrm{m}$ polytetrafluoroethylene filter (PTFE, Sartorius Stedim). As pores of the filter are bigger than single nanotubes, only the network of nanotubes formed during the filtration is retained. This confers a real self-standing behavior to our BPs as the excess of MWCNT are thus removed. The BP thus formed is washed with acetone, removed from the supporting filter membrane and finally dried under vacuum at $150{ }^{\circ} \mathrm{C}$ overnight.

\section{Buckypaper structural characterizations}

Gas sorption isotherms were recorded using Tristar II 3020 Micromeritics equipment under $\mathrm{N}_{2}$ gas atmosphere at $77 \mathrm{~K}$. Pore size distribution and mean pore size were calculated using the Barrett, Joyner and Halenda (BJH) method. Calculations of the specific surface area (SSA) were achieved using the Brunauer-Emmett-Teller (BET) equation. SEM observations were made using a FEG-SEM (Jeol JSM 6700F).

\section{Cell assembly and electrochemical characterizations}

Cells were assembled in a glove box (under inert $\mathrm{Ar}$ atmosphere, 5.0 purity grade) with both water and oxygen content lower than $0.1 \mathrm{ppm}$. Two-electrode cells were assembled by inserting a $520-\mu \mathrm{m}$ thick glass fiber separator (GF/B, Whatman) between the two electrodes, whose diameter were $9 \mathrm{~mm}$ and mass $5.6 \mathrm{mg}$, in a symmetric twoelectrode Swagelok ${ }^{\circledR}$ configuration (Fig. 1). As no current collectors were used, BP electrodes were directly in contact with cylindrical stainless steel plungers (diameter $=$ $12 \mathrm{~mm}$ ). Two electrolytes were tested: (1) tetraethylammonium tetrafluoroborate $\left(\mathrm{NEt}_{4} \mathrm{BF}_{4}, 99 \%\right.$, Acros Organics) $1 \mathrm{M}$ dissoluted in acetonitrile (AN, $99.9 \%$ extra dry Acroseal ${ }^{\circledR}$, Acros Organics) and (2) an eutectic mixture of ionic liquids (1:1 in molar ratio), $N$-methyl- $N$-propylpiperidinium bis(fluorosulfonyl)imide ( $\mathrm{PIP}_{13} \mathrm{FSI}, 99.9 \%$, Solvionic) and $N$-butyl- $N$-methylpyrrolidinium bis(fluorosulfonyl)imide (PYR ${ }_{14}$ FSI, $99.9 \%$, Solvionic) [10].

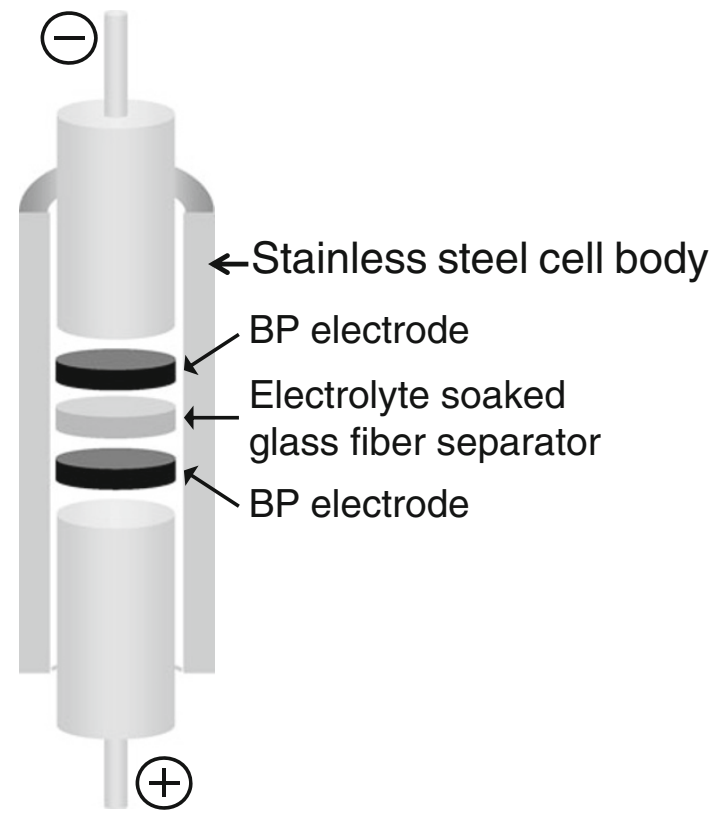

Fig. 1 Schematic of a symmetric two-electrode Swagelok ${ }^{\circledR}$ (stainless steel plungers) electrochemical double layer capacitor: the electrolyte $\left(\mathrm{NEt}_{4} \mathrm{BF}_{4} 1 \mathrm{M}\right.$ in $\mathrm{AN}$ or ILs eutectic mixture) soaked glass fiber separator $(\mathrm{GF} / \mathrm{B}$, Whatman) is sandwiched between to BP electrodes, whose diameter is $9 \mathrm{~mm}$ and mass is $5.6 \mathrm{mg}$

Electrochemical measurements were done with a Biologic VMP3 potentiostat for room temperature experiments and a Biologic SP-200 potentiostat for low and high temperatures measurements. Swageloks ${ }^{\circledR}$ were directly connected to Biologic ${ }^{\circledR}$ instruments as channels' wires were inserted in plungers' holes. Electrochemical impedance spectroscopy (EIS) experiments were achieved at a bias voltage of $0 \mathrm{~V}$. A sinusoidal voltage perturbation $(\Delta V= \pm 10 \mathrm{mV})$ was applied in a frequency range from $200 \mathrm{kHz}$ to $10 \mathrm{mHz}$ for AN-based electrolyte, and to $200 \mu \mathrm{Hz}$ for ILs mixture. Cyclic voltammetries (CVs) were performed at various scan rates. To compare capacitances obtained at different scan rates, intensities were divided by the corresponding scan rate. Temperature control was achieved using a Vötsch climatic chamber with the temperature being additionally checked by a thermocouple. If not otherwise specified, reported capacitances concern the BP material by itself, and not of the full EDLC.

\section{Results and discussion}

SEM observations and gas sorption measurements

SEM micrograph shows randomly organized multi-walled carbon nanotubes (MWCNTs) (Fig. 2a) that confers flexibility to the material (inset Fig. 2a). The adsorption isotherm (Fig. 2b) is of type IV, with a progressive increase in 

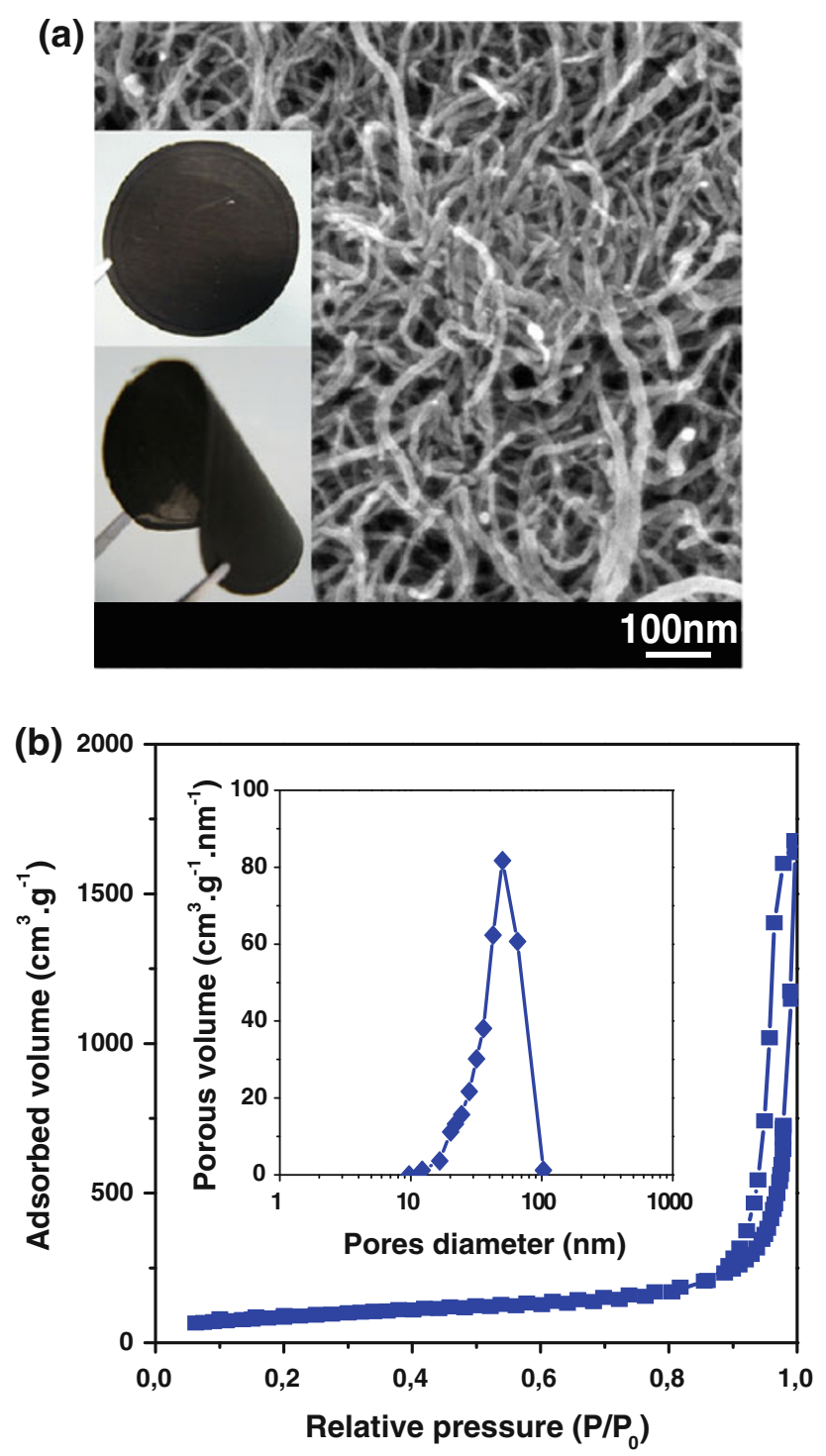

Fig. 2 a SEM micrograph of a BP electrode highlighting the entanglement of carbon nanotubes allowing its (inset) self-standing and flexible behaviors; b Type $\mathrm{V}$ isotherm characteristic of a mesoporous material with its derived pore size distribution

the gas adsorbed volume until $0.9 P / P_{0}$. The isotherm shows an inflection and hysteresis loop H1 (adsorption and desorption curves are parallel and almost vertical) for $P / P_{0}>0.9$ which is typical from a mesoporous material with a narrow pore distribution. This is confirmed by the BJH calculation that gives a mean pore size of $40 \mathrm{~nm}$ (inset). The calculated SSA, calculated by the BET equation, is about $310 \mathrm{~m}^{2} \mathrm{~g}^{-1}$.

Electrochemical measurement in $\mathrm{NEt}_{4} \mathrm{BF}_{4} 1 \mathrm{M}$ in $\mathrm{AN}$ electrolyte

In a first step, buckypaper electrodes have been tested in a conventional electrolyte: $1 \mathrm{M} \mathrm{NEt}_{4} \mathrm{BF}_{4}$ dissolved in
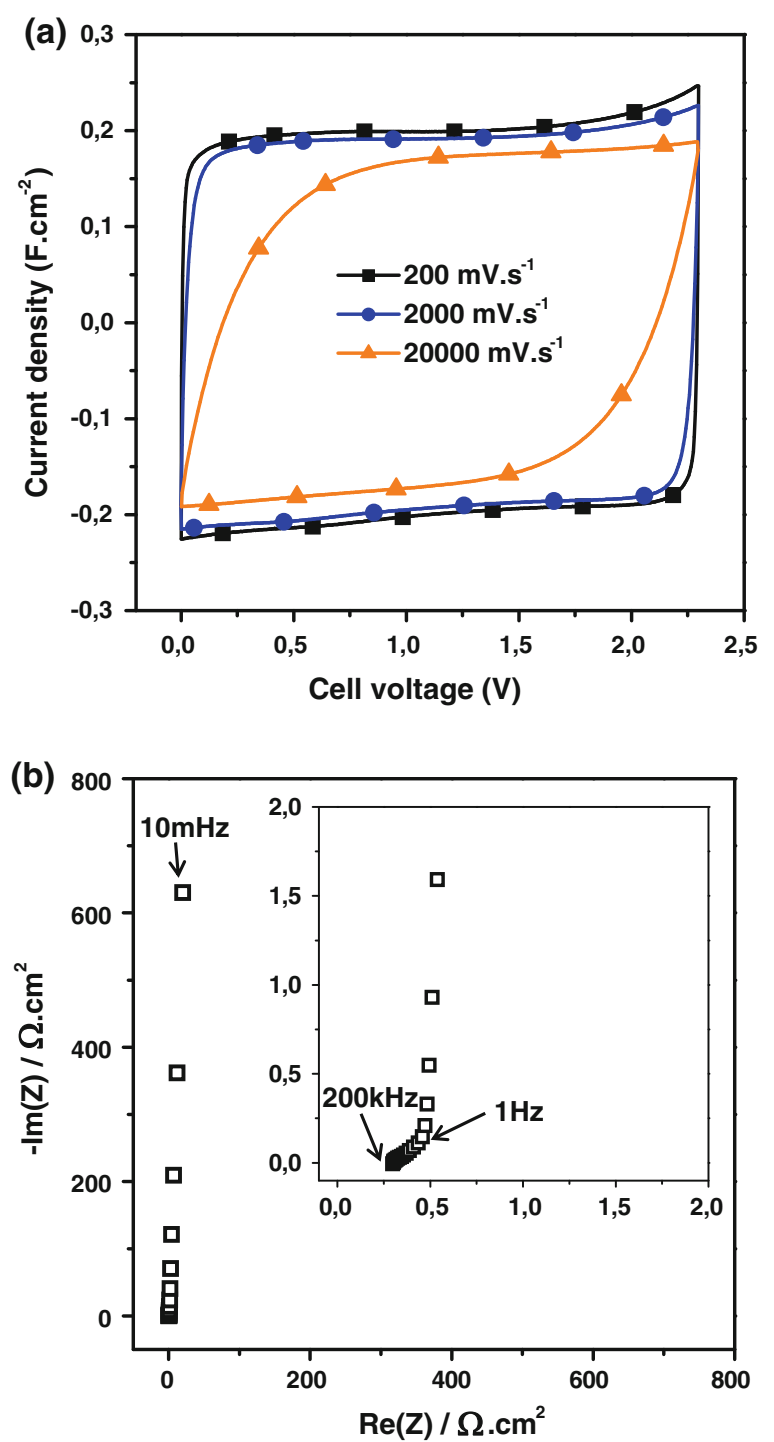

Fig. 3 a $\mathrm{CVs}$ of symmetric $\mathrm{BPs} / \mathrm{NET}_{4} \mathrm{BF}_{4}-\mathrm{AN}$ cell obtained at room temperature $\left(+25^{\circ} \mathrm{C}\right)$ in the $0-2.3 \mathrm{~V}$ potential range at (filled squares) $200 \mathrm{mV} \mathrm{s}^{-1}$, (filled circles) $2,000 \mathrm{mV} \mathrm{s}^{-1}$, (filled triangles) $20,000 \mathrm{mV} \mathrm{s}^{-1}$ scan rates ( $y$ axis is plotted in $\mathrm{F} \mathrm{cm}^{-2}$ ); $\mathbf{b}$ the corresponding Nyquist plot

acetonitrile (AN) that allows operation temperature range from -40 to $+70{ }^{\circ} \mathrm{C}$. Figure $3 \mathrm{a}$ shows the room temperature $\mathrm{CV}$ plots of a two-electrode cell assembled with our BP electrodes at various scan rates. All the CVs show the rectangular-shape electrochemical signature typical for a capacitive behavior within the $0-2.3 \mathrm{~V}$ potential range. Besides, high power and flexible applications are possible as the capacitive behavior is preserved at scan rates as high as $20 \mathrm{~V} \mathrm{~s}^{-1}$. The Nyquist plot (Fig. 3b) confirms this good capacitive behavior, with a fast increase of the imaginary part at low frequencies. The behavior shown is a series-resistance/ capacitor-circuit with clear evidence of porous electrode behavior. Ionic resistance in the porous network 
and the equivalent series resistance (ESR at $1 \mathrm{kHz}$ ) are comparable in values.

However, the operation temperature range of acetonitrile-based EDLC is limited by the boiling point of AN $\left(81^{\circ} \mathrm{C}\right)$, as well as the toxicity of potential degradation products and its low flash point $\left(\approx 5^{\circ} \mathrm{C}\right)[6,7]$. Replacing AN by propylene carbonate (PC) drastically limits the power performances because of the lower ionic conductivity of PC-based electrolytes. Additionally, operating temperature using $\mathrm{PC}$-based electrolytes is restricted between -25 and $+70{ }^{\circ} \mathrm{C}[6,7]$ which is not sufficient for outdoor operation in severe environment, like the use of flexible EDLCs in smart-textile uses, for military applications. Working temperatures lower than $-60{ }^{\circ} \mathrm{C}$ were reported by Brandon and co-workers [19-21], by adding different co-solvents with low boiling points such as methyl formate, methyl acetate or 1,3 dioxolane, in ANbased electrolytes. However, the maximum operation temperature was limited to $+50{ }^{\circ} \mathrm{C}$ [19-21].

Electrochemical measurement in eutectic mixture of ionic liquids

Ionic liquids (ILs) are solvent free that can be used at high temperatures because they show negligible vapor pressure, are non-flammable and non-toxic. However, despite their large electrochemical stability window beyond $3 \mathrm{~V}$ leading to important energy density increase ( $E$ proportional to $V^{2}$ ), their low ionic conductivity and high viscosity still limit their use in electrochemical energy storage devices [22-24]. Room temperature IL electrolytes for EDLCs were developed in combination with activated carbon [25], carbon nanotubes [26] or graphene electrodes [27]. To extend the temperature operation range of our buckypapers-based EDLCs, we used an eutectic ILs mixture we recently developed [10].

Figure 4 shows $\mathrm{CV}$ s obtained at room temperature for two-electrode EDLC system in the $50 \% \mathrm{PIP}_{13} \mathrm{FSI} / 50 \%$ $\mathrm{PYR}_{14} \mathrm{FSI}$ mixture. The rectangular shape of the CVs evidences a capacitive behavior. However, as expected, the lower conductivity of the mixture (Table 1) limits the rate capability of the electrode to $500 \mathrm{mV} \mathrm{s}^{-1}$. Cyclic voltammetries were performed at $+100,+25,-40$ and $-50{ }^{\circ} \mathrm{C}$ and are reported (Fig. 5a, b). As shown in Fig. 5a), the CV recorded at high temperature $\left(+100{ }^{\circ} \mathrm{C}\right)$ for a scan rate of $100 \mathrm{mV} \mathrm{s}^{-1}$ shows a nice capacitive behavior too. More, the improvement in conductivities at high temperature allows a wider range of speed rates up to $2 \mathrm{~V} \mathrm{~s}^{-1}$ before being limited by the ohmic drop. The additional advantage of this eutectic mixture of ionic liquids is the wide range of temperatures, and more at low temperature, compared to pure ionic liquids used separately. The limitation is due to conductivities becoming too poor under $-50{ }^{\circ} \mathrm{C}$ (Table 1)

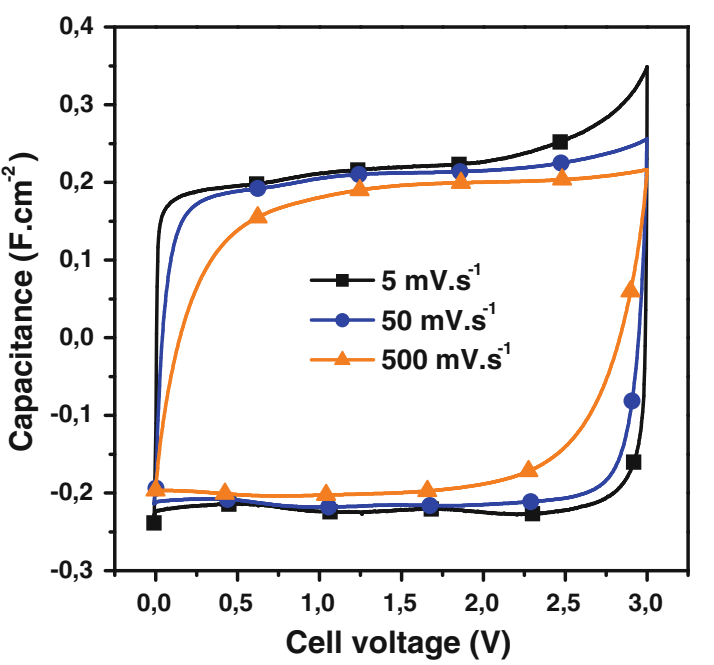

Fig. $4 \mathrm{CVs}$ of symmetric BPs/ILs mixture cell obtained at room temperature $\left(+25^{\circ} \mathrm{C}\right)$ in the $0-3 \mathrm{~V}$ potential range at (filled squares) $5 \mathrm{mV} \mathrm{s}^{-1}$, (filled circles) $50 \mathrm{mV} \mathrm{s}^{-1}$, (filled triangles) $500 \mathrm{mV} \mathrm{s}^{-1}$ scan rates $\left(y\right.$ axis is plotted in $\mathrm{F} \mathrm{cm}^{-2}$ )

Table 1 Conductivity of the ILs eutectic mixture as a function of temperature

\begin{tabular}{ll}
\hline Temperature $\left({ }^{\circ} \mathrm{C}\right)$ & Conductivity $\left(\mathrm{S} \mathrm{cm}^{-1}\right)$ \\
\hline+100 & $2.9 \times 10^{-2}$ \\
+25 & $5.9 \times 10^{-3}$ \\
-40 & $5.7 \times 10^{-5}$ \\
-50 & $1.5 \times 10^{-5}$ \\
-70 & $6.8 \times 10^{-7}$ \\
\hline
\end{tabular}

[28]. Figure $5 \mathrm{~b}$ shows nice capacitive behaviors still preserved at -40 and $-50{ }^{\circ} \mathrm{C}$ for a scan rate of $1 \mathrm{mV} \mathrm{s}^{-1}$. The lower the working temperature, the lower the conductivity and, consequently, the potential scan rate is decreased down to 5 and $2 \mathrm{mV} \mathrm{s}^{-1}$ at -40 and $-50{ }^{\circ} \mathrm{C}$, respectively. A comparison of the different capacitances obtained in different electrolytes and temperatures will be discussed and compared with literature in "Capacitances vs. electrolytes and scan rates".

Figure 6 shows Nyquist plots for the symmetric BPs cell at different temperatures assembled using the ionic liquid mixture electrolyte. All plots confirm results obtained by CVs as they show a classical capacitive behavior, with a high increase of their imaginary part at low frequencies. Going from $+100{ }^{\circ} \mathrm{C}$ down to $-50^{\circ} \mathrm{C}$, the huge difference is seen at medium frequencies where the low-frequency capacitive behavior is shifted to higher resistances. A main difference with AN-based electrolyte is the presence of a semi-circle at high frequencies, showing an evolution too with temperature. Both differences, at high and medium frequencies, are due to the high difference of ILs mixture viscosity, which is temperature dependent (Table 1), 

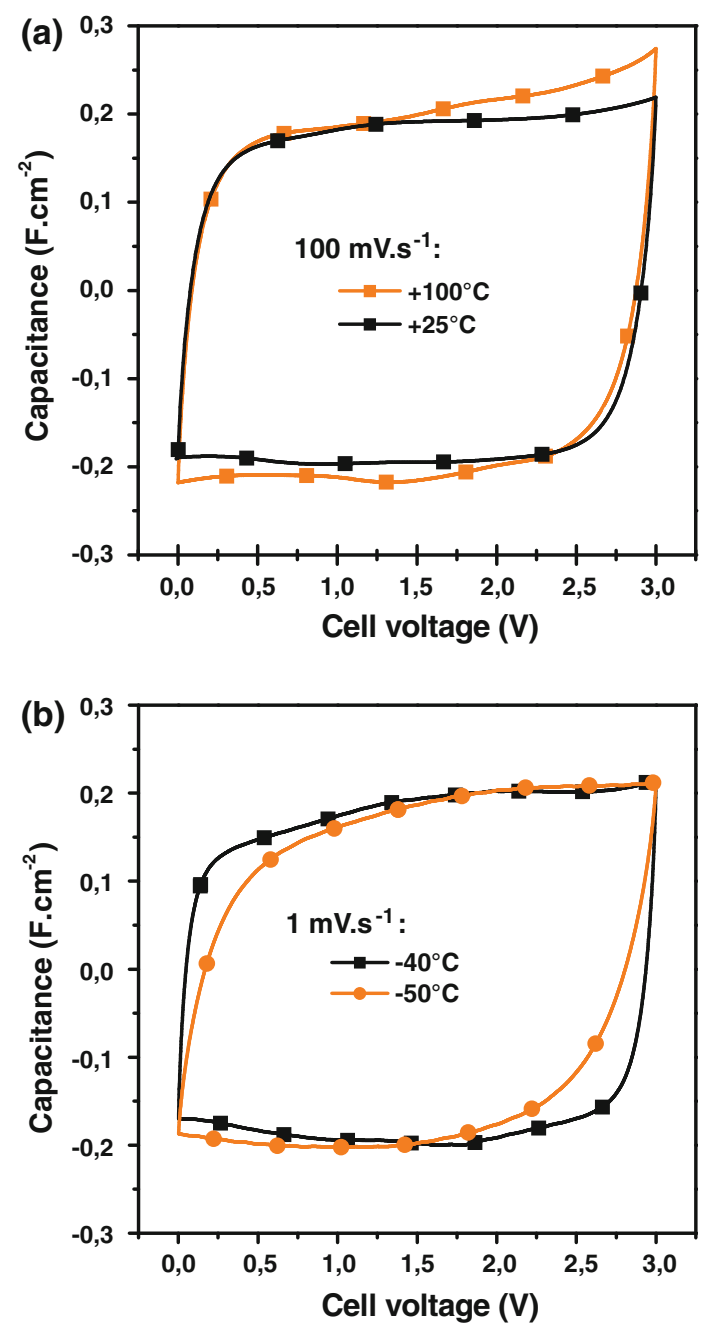

Fig. $5 \mathrm{CVs}$ of symmetric BPs/ILs mixture cell cycled in the $0-3 \mathrm{~V}$ potential range a at $100 \mathrm{mV} \mathrm{s}^{-1}$ obtained at (filled circles) $+100{ }^{\circ} \mathrm{C}$ and (filled squares) $+25^{\circ} \mathrm{C}$ and $\mathbf{b}$ at $1 \mathrm{mV} \mathrm{s}^{-1}$ obtained at (filled circles) $-40{ }^{\circ} \mathrm{C}$ and (filled squares) $-50{ }^{\circ} \mathrm{C}$ ( $y$ axis is plotted in $\mathrm{F} \mathrm{cm}^{-2}$ )

leading to a difference in the ionic conductivity of the electrolyte inside the porous structure of the BPs, compared to AN-based electrolyte [29].

Capacitances vs. electrolytes and scan rates

Figure 7 summarizes results of cycling experiments, where delivered capacitances are reported as a function of scan rates. Buckypapers show excellent power performance and similar delivered capacitances, whatever electrolytes and temperatures used. Using the eutectic ILs mixture, the maximum capacitance was obtained at $+100{ }^{\circ} \mathrm{C}$ and $1 \mathrm{mV} \mathrm{s}^{-1}$ with $0.24 \mathrm{~F} \mathrm{~cm}^{-2}\left(131.9 \mathrm{~F} \mathrm{~cm}^{-3}, 26.8 \mathrm{~F} \mathrm{~g}^{-1}\right)$. The capacitance values ranged from this maximum down to $0.18 \mathrm{~F} \mathrm{~cm}^{-2}\left(98.9 \mathrm{~F} \mathrm{~cm}^{-3}, 20.0 \mathrm{~F} \mathrm{~g}^{-1}\right)$, obtained at

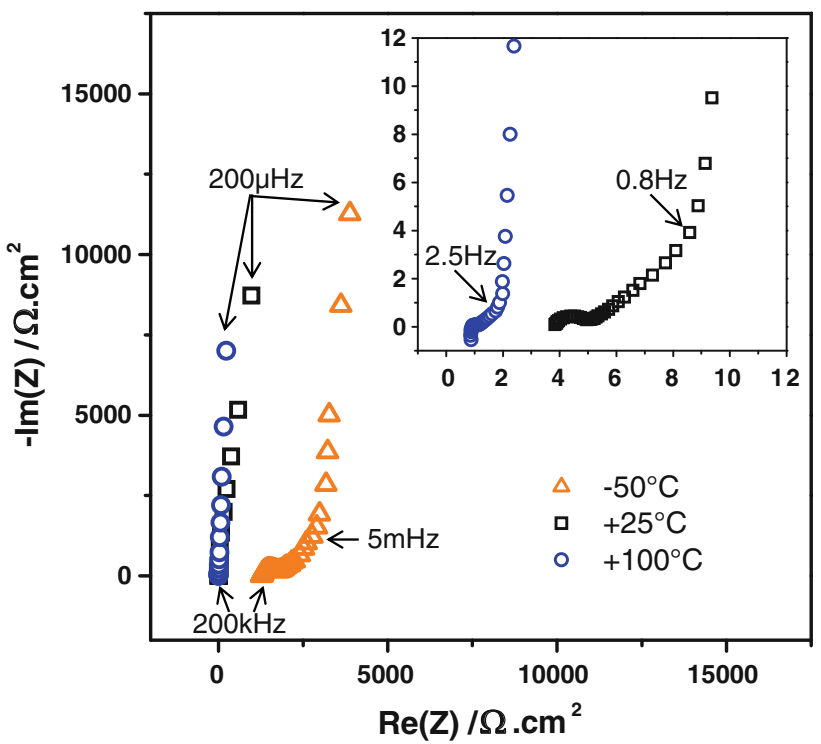

Fig. 6 Nyquist plots of symmetric EDLCs made with the ILs mixture as electrolyte at (open circles) $+100{ }^{\circ} \mathrm{C}$, (open squares) $+25^{\circ} \mathrm{C}$ and (open triangles) $-50{ }^{\circ} \mathrm{C}$

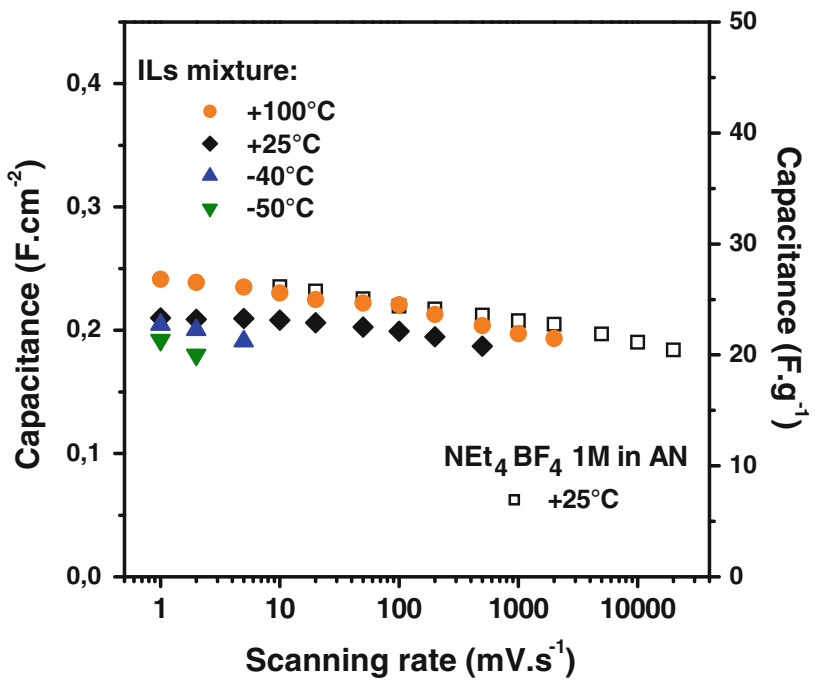

Fig. 7 Capacitances depending on the working temperature delivered by BPs electrodes in ILs mixture and AN-based electrolyte as a function of scan rates

$-50{ }^{\circ} \mathrm{C}$ and $2 \mathrm{mV} \mathrm{s}^{-1}$. As scan rates range is lower than the one possible to use with AN-based electrolyte, our EDLC cannot be used for high power applications.

Previous results were obtained with onion-like carbons (OLC) and vertically aligned CNT (VA-CNT) [10]. VACNTs were grown directly on aluminum foils via plasmaenhanced chemical vapor deposition in a cold wall reactor. OLCs, mixed with $5 \mathrm{wt} \%$ PTFE, can be visualized as multi-shell fullerenes with concentric graphitic shells. Both types of materials were tested in Swagelok ${ }^{\circledR}$ cells using two layers of a $25-\mu \mathrm{m}$ thick porous alumina separator. 
Using our EDLC made of BP electrodes, ILs mixture electrolyte and glass fiber separator, surfaced capacitances were increased by a factor 2 compared to OLC $\left(0.1 \mathrm{~F} \mathrm{~cm}^{-2}\right)$ and by a factor 50 compared to VA-CNT $\left(0.04 \mathrm{~F} \mathrm{~cm}^{-2}\right)$ [10]. Those previous results together with the ones presented here definitely show that with this ILs electrolyte mixture, the use of mesoporous carbon electrodes is recommended, because of the high viscosity and the low conductivity of such kind of electrolytes. Furthermore, an excellent affinity is also obtained thanks to hydrophobic nature of those two compounds, namely the carbon and the IL mixture. Thus, these results definitely confirm that best performances can be achieved when electrolyte and electrode fit perfectly each other (chemically and physically speaking).

\section{Conclusion}

With this study, we could show the feasibility to build EDLCs able to work safely under severe conditions for smart-textile applications. We were able to cycle our EDLC between -50 and $+100{ }^{\circ} \mathrm{C}$ without losing performance. The key point of using buckypapers is to get a standalone electrode without the use of any binders or current collectors. This reduces significantly the total mass of the EDLC, what is a benefit for energy densities but also for its incorporation in textiles. An effort has to be made to decrease the resistivity of whole system BP-electrolyte at higher scan rates. Meantime, at suitable temperatures, the AN-based electrolyte can be used for power applications.

Acknowledgments Authors would like to thank the ANR for financial support for this work (Progelec program). C.L., B.D., R.L., P.L.T. and P.S. thank the THALES company (Research \& Technology department) for supporting this work.

Open Access This article is distributed under the terms of the Creative Commons Attribution License which permits any use, distribution, and reproduction in any medium, provided the original author(s) and the source are credited.

\section{References}

1. Simon, P., Gogotsi, Y.: Materials for electrochemical capacitors. Nat Mater 7(11), 845-854 (2008)

2. Faggioli, E., Rena, P., Danel, V., Andrieu, X., Mallant, R., Kahlen, H.: Supercapacitors for the energy management of electric vehicles. J. Power Sources 84(2), 261-269 (1999)

3. Miller, J.R., Simon, P.: Electrochemical capacitors for energy management. Science 321(5889), 651-652 (2008)

4. Kötz, R., Carlen, M.: Principles and applications of electrochemical capacitors. Electrochim. Acta 45(15-16), 2483-2498 (2000)

5. Burke, A.: Ultracapacitors: why, how, and where is the technology. J. Power Sources 91(1), 37-50 (2000)
6. Dash, R., Chmiola, J., Yushin, G., Gogotsi, Y., Laudisio, G., Singer, J., Fischer, J., Kucheyev, S.: Titanium carbide derived nanoporous carbon for energy-related applications. Carbon 44(12), 2489-2497 (2006)

7. Dzubiella, J., Hansen, J.P.: Electric-field-controlled water and ion permeation of a hydrophobic nanopore. J. Chem. Phys. 122(23), 234706-234714 (2005)

8. Miller, J.R., Burke, A.F.: Electrochemical capacitors: challenges and opportunities for real-world applications. Interface 17(1), 53-57 (2008)

9. Cherenack, K., Zysset, C., Kinkeldei, T., Munzenrieder, N., Troster, G.: Woven electronic fibers with sensing and display functions for smart textiles. Adv. Mater. 22(45), 5178-5182 (2010)

10. Lin, R., Taberna, P.L., Fantini, S., Presser, V., Perez, C.R., Malbosc, F., Rupesinghe, N.L., Teo, K.B.K., Gogotsi, Y., Simon, P.: Capacitive energy storage from -50 to $100{ }^{\circ} \mathrm{C}$ using an ionic liquid electrolyte. J. Phys. Chem. Lett. 2(19), 2396-2401 (2011)

11. Izadi-Najafabadi, A., Yamada, T., Futaba, D.N., Yudasaka, M., Takagi, H., Hatori, H., Iijima, S., Hata, K.: High-power supercapacitor electrodes from single-walled carbon nanohorn/ nanotube composite. ACS Nano 5(2), 811-819 (2011)

12. Liu, J., Rinzler, A.G., Dai, H., Hafner, J.H., Bradley, R.K., Boul, P.J., Lu, A., Iverson, T., Shelimov, K., Huffman, C.B., Rodriguez-Macias, F., Shon, Y.S., Lee, T.R., Colbert, D.T., Smalley, R.E.: Fullerene pipes. Science 280(5367), 1253-1256 (1998)

13. Endo, M., Muramatsu, H., Hayashi, T., Kim, Y.A., Terrones, M., Dresselhaus, M.S.: Nanotechnology: 'buckypaper' from coaxial nanotubes. Nature 433(7025), 476 (2005)

14. Bahr, J.L., Yang, J.P., Kosynkin, D.V., Bronikowski, M.J., Smalley, R.E., Tour, J.M.: Functionalization of carbon nanotubes by electrochemical reduction of aryl diazonium salts: a bucky paper electrode. J. Am. Chem. Soc. 123(27), 6536-6542 (2001)

15. Hu, L., Chen, W., Xie, X., Liu, N., Yang, Y., Wu, H., Yao, Y., Pasta, M., Alshareef, H.N., Cui, Y.: Symmetrical $\mathrm{MnO}_{2}$ - carbon nanotube-textile nanostructures for wearable pseudocapacitors with high mass loading. ACS Nano 5(11), 8904-8913 (2011)

16. Jost, K., Perez, C.R., McDonough, J.K., Presser, V., Heon, M., Dion, G., Gogotsi, Y.: Carbon coated textiles for flexible energy storage. Energy Environ. Sci. 4(12), 5060-5067 (2011)

17. O'Connel, M.J., Boul, P., Ericson, L.M., Huffman, C., Wang, Y., Haroz, E., Kuper, C., Tour, J., Ausman, K.D., Smaley, R.E.: Reversible water-solubilization of single-walled carbon nanotubes by polymer wrapping. Chem. Phys. Lett. 342(3-4), 265-271 (2001)

18. Zhang, M., Yudaska, M., Koshio, A., Iijima, S.: Effect of polymer and solvent on purification and cutting of single-wall carbon nanotubes. Chem. Phys. Lett. 349(1-2), 25-30 (2001)

19. Brandon, E.J., Smart, M.C., West, W.C.: Low-temperature supercapacitors. NASA Tech Briefs 32, 32 (2008)

20. West, W.C., Smart, M.C., Brandon, E.J., Whitcanack, L.D., Plett, G.A.: Double-layer capacitor electrolytes using 1,3-D ioxolane for low temperature operation. J. Electrochem. Soc. 155(10), A716-A720 (2008)

21. Brandon, E.J., West, W.C., Smart, M.C., Whitcanack, L.D., Plett, G.A.: J. Power Sources 170, 225-232 (2007)

22. Armand, M., Endres, F., MacFarlane, D.R., Ohno, H., Scrosati, B.: Ionic-liquid materials for the electrochemical challenges of the future. Nat. Mater. 8(8), 621-629 (2009)

23. Torimoto, T., Tsuda, T., Okazaki, K., Kuwabata, S.: New frontiers in materials science opened by ionic liquids. Adv. Mater. 22(11), 1196-1221 (2010)

24. Balducci, A., Dugas, R., Taberna, P.L., Simon, P., Plée, D., Mastragostino, M., Passerini, S.: High temperature carbon-carbon supercapacitor using ionic liquid as electrolyte. J. Power Sources 165(2), 922-927 (2007) 
25. Wei, D., Ng, T.W.: Application of novel room temperature ionic liquids in flexible supercapacitors. Electrochem. Commun. 11(10), 1996-1999 (2009)

26. Lu, W., Qu, L., Henry, K., Dai, L.: High performance electrochemical capacitors from aligned carbon nanotube electrodes and ionic liquid electrolytes. J. Power Sources 189(2), 1270-1277 (2009)

27. Zhu, Y., Murali, S., Stoller, M.D., Ganesh, K.J., Cai, W., Ferreira, P.J., Pirkle, A., Wallace, R.M., Cychosz, K.A., Thommes, M., Su, D., Stach, E.A., Ruoff, R.S.: Carbon-based supercapacitors produced by activation of graphene. Science 332(6037), 1537-1541 (2011)

28. Kunze, M., Jeong, S., Paillard, E., Winter, M., Passerini, S.: Melting behavior of pyrrolidinium-based ionic liquids and their binary mixtures. J. Phys. Chem. C 114(28), 12364-12369 (2010)

29. Taberna, P.L., Simon, P., Fauvarque, J.F.: Electrochemical characteristics and impedance spectroscopy studies of carboncarbon supercapacitors. J. Electrochem. Soc. 150(3), A292-A300 (2003) 